\title{
DEVELOPMENT OF IMPROVED BOND COAT FOR ENHANCED TURBINE DURABILITY
}

\author{
Brian Hazel $^{1}$, Joe Rigney ${ }^{1}$, Mark Gorman ${ }^{1}$, Brett Boutwell ${ }^{1}$, Ram Darolia ${ }^{1}$ \\ ${ }^{1}$ General Electric Aviation; One Neumann Way, Cincinnati, OH, 45215, USA
}

Keywords: coatings, bond coat, thermal barrier coating, TBC adherence, oxidation

\begin{abstract}
Intermetallic alloy development in the early 1990's suggested that zirconium additions to the $\mathrm{NiAl}$ system could significantly strengthen the bond coat and prevent surface rumpling that leads to failure of the thermal barrier coating (TBC) system. A new overlay bond coat based on $\mathrm{NiAl}$ that incorporates zirconium and chromium has been developed. Additions of both zirconium and chromium were found to be beneficial for TBC adherence and environmental resistance of the bond coat. Overlay processing methods were used to produce the coating in order to accurately control the zirconium and chromium content. Furthermore, the overlay coating incorporated substrate elements, like nickel, to reduce interdiffusion with the substrate. This reduced interdiffusion resulted in greater retention of the load bearing area of the substrate after extended time at temperature. A gas turbine engine was run with both the new overlay bond coat and current diffusion platinum aluminide bond coat for direct comparison. The new $\mathrm{NiAl}+\mathrm{Cr}+\mathrm{Zr}$ overlay bond coat demonstrated improved durability and better protection of the underlying substrate in comparison with the current state of the art diffusion platinum aluminide bond coat.
\end{abstract}

\section{Introduction}

Higher operating temperatures for gas turbine engines are continuously sought in order to increase efficiency. As operating temperatures increase, the high temperature durability of the engine components must also correspondingly increase. Significant advances in high temperature capability have been achieved through formulations of iron, nickel, and cobalt-base superalloys, though such alloys alone are often inadequate for components located in certain sections of a gas turbine engine, such as the turbine, combustor, and augmentor [1]. A common solution is to protect these components with either an oxidationresistant coating or a thermal barrier coating (TBC) system. Diffusion coatings, such as diffusion aluminides, and overlay coatings such as MCrAlY (where $\mathrm{M}$ is iron, cobalt, and/or nickel) have been widely employed as environmental coatings and as bond coats for TBC systems. In the most demanding applications, insulating ceramic TBCs are applied over the diffusion aluminides to further reduce the bulk and surface temperatures of the component [2]. The use of advanced environmental coatings and TBC systems in turbine engines has increased substantially over the last twenty years.

During the past decade, GE-Aviation has been working on programs to develop and implement TBC systems with enhanced thermal benefit and durability. Prior TBC systems were created by simply adding an insulating ceramic layer over top of conventional coatings developed for environmental resistance [3]. These historical "bond coat" systems have performed well, however, a new bond coat system was designed and developed to improve TBC spallation durability, while meeting other performance and producibility requirements. To achieve this, the coating composition was specifically engineered to delay or reduce the magnitude of bond coat rumpling that typically precedes TBC spallation in conventional aluminide systems $[4,5$, $6]$.

New bond coat alloying approaches were initially conceived after evaluating monolithic NiAl intermetallics as structural materials in the early 1990's. Reactive element-doped NiAl coupons (Figure 1) coated with TBC and tested to spallation failure showed that minor additions of $\mathrm{Hf}$ or $\mathrm{Zr}$ to $\mathrm{NiAl}$ provided substantial increases in the thermal spallation life of the system [2, 7]. The improvement was linked, in part, to an increase in the high temperature strength of the beta NiAl based alloy. A program was initiated to translate the improved environmental performance of these structural alloys into a new bond coat system with advantages over traditional diffusion based aluminide coatings.

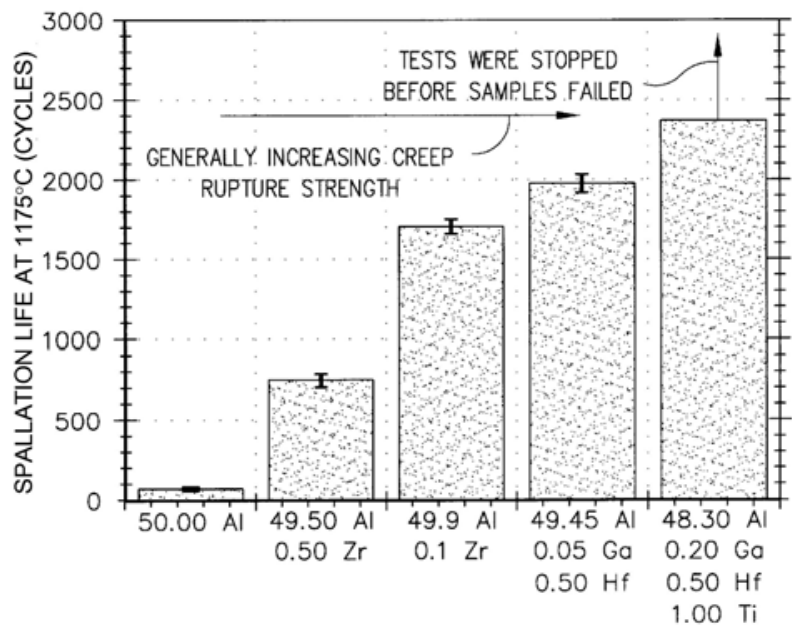

NICKEL ALUMINIDE ALLOY COMPOSITION

Figure 1. TBC spallation life of monolithic NiAl intermetallics with minor element additions (compositions in atomic \%) [7]

The objective of this program was to define an overlay coating composition with substantially improved TBC spallation durability over that of the current noble-metal modified aluminides.

(C) 2008, General Electric Company All Rights Reserved 


\section{Procedure}

Test coupons were machined from investment cast single crystal René N5 (nominal composition in weight percent of 7.5\% Co, 7.0\% Cr, 6.5\% Ta, 6.2\% Al, 5.0\% W, 3.0\% Re, 1.5\% Mo, 0.15\% Hf, $0.05 \%$ C, $0.004 \% \mathrm{~B}, 0.01 \% \mathrm{Y}$, the balance nickel) $25.4 \mathrm{~mm}$ diameter rods or $12.7 \mathrm{~mm} \times 50 \mathrm{~mm} \times 127 \mathrm{~mm}$ slabs. The test coupons were either $25 \mathrm{~mm}$ diameter by $3.2 \mathrm{~mm}$ thick "buttons" or $6.2 \mathrm{~mm}$ diameter by $89 \mathrm{~mm}$ long "pins" both with a surface finish of $<0.8 \mu \mathrm{m}$. The surfaces of the coupons were first cleaned with isopropyl alcohol and then prepared by grit blasting with alumina media prior to coating. Samples were coated with a single phase diffusion platinum aluminide produced by a proprietary abovethe-pack process to act as a baseline comparison.

A first set of experiments utilized an electron-beam physical vapor deposition (EB-PVD) technique to deposit $\mathrm{NiAl}+\mathrm{Cr}+\mathrm{Zr}$ overlay coatings. The EB-PVD process conditions were varied to adjust the zirconium content from one sample set to another while maintaining a chromium level of 5 at $\%$ and an aluminum to nickel ratio of about 1:1. The coatings were deposited to a thickness of about $50 \mu \mathrm{m}$ and included a range of zirconium from $0.1-1.2 \mathrm{at} \%$. The as-processed coatings were vacuum heat treated at $1093^{\circ} \mathrm{C}$ for 2 hours. Following the bond coat application, the samples where coated with a $125 \mu \mathrm{m}$ thick $7 \mathrm{wt} \%$ yttria stabilized zirconia TBC by Praxair Surface Technologies using an EB-PVD process. TBC spallation lives for $\mathrm{NiAl}+\mathrm{Cr}+\mathrm{Zr}$ coatings were measured in a furnace cycle test (FCT) in which TBC coated button samples were thermally exposed in a bottom loading box furnace manufactured by CM Furnaces Inc. Each FCT cycle was 1 hour in duration with a hold temperature of $1163^{\circ} \mathrm{C}$ for 45 minutes per cycle. Samples were inspected at 20 cycle intervals and considered failed once $20 \%$ area spallation of the TBC occurred.

A second set of $\mathrm{NiAl}+\mathrm{Cr}+\mathrm{Zr}$ overlay coating experiments were conducted to determine the interaction effects of zirconium and chromium additions in NiAl. For this work a high velocity oxyfuel (HVOF) coating process was used as a means to more accurately vary the zirconium and chromium content. Powders for HVOF processing were produced according to Table I with an aluminum to nickel ratio of about 1:1.

Table I: Chromium and Zirconium Levels of Powder Chemistries for HVOF Experiment

\begin{tabular}{|l|c|c|}
\cline { 2 - 3 } \multicolumn{1}{c|}{} & $\begin{array}{c}\text { Cr } \\
\text { (atomic\%) }\end{array}$ & $\begin{array}{c}\mathrm{Zr} \\
\text { (atomic\%) }\end{array}$ \\
\hline Powder \#1 & 2 & 0.1 \\
\hline Powder \#2 & 5 & 0.1 \\
\hline Powder \#3 & 10 & 0.1 \\
\hline Powder \#4 & 2 & 0.3 \\
\hline Powder \#5 & 5 & 0.3 \\
\hline Powder \#6 & 10 & 0.3 \\
\hline Powder \#7 & 2 & 0.5 \\
\hline Powder \#8 & 5 & 0.5 \\
\hline Powder \#9 & 10 & 0.5 \\
\hline Powder \#10 & 2 & 0.7 \\
\hline Powder \#11 & 5 & 0.7 \\
\hline Powder \#12 & 10 & 0.7 \\
\hline
\end{tabular}

Coatings were sprayed to a thickness of $50 \mu \mathrm{m}$ on pin samples. The as-processed coatings were vacuum heat treated at $1080^{\circ} \mathrm{C}$ for 2 hours. Due to the roughness of the HVOF processed coatings, a hand polishing process was used to reduce the surface roughness after heat treatment. Following the bond coat application, the samples where coated with a $125 \mu \mathrm{m}$ thick $7 \mathrm{wt} \%$ yttria stabilized zirconia TBC by Praxair Surface Technologies using an EB-PVD process. The TBC coated samples were subjected to a burner rig cyclic test to measure the TBC spallation lives. Each cycle was approximately 6.5 minutes in duration with a hold temperature of $1135^{\circ} \mathrm{C}$ for 5 minutes followed by a 75 second forced air cool to about $93^{\circ} \mathrm{C}$. Samples were inspected at 20 cycle intervals with failure defined by the first occurrence of coating spallation. Additionally, a combined hot corrosion and oxidation (CHCO) burner rig test was used to determine environmental resistance of the coating. Each $\mathrm{CHCO}$ cycle was approximately 17 minutes in duration with a first hold temperature of $927^{\circ} \mathrm{C}$ for 10 minutes during which the combustion gas was contaminated with sea salt and a second hold temperature of $1135^{\circ} \mathrm{C}$ for 5 minutes per cycle followed by a forced air cool to about $93^{\circ} \mathrm{C}$. Samples were inspected at 48 hour intervals and considered failed once the coating is breached (evident from the formation of non-protective blue/green oxide).

Additional EB-PVD and HVOF processed $\mathrm{NiAl}+\mathrm{Cr}+\mathrm{Zr}$ coatings were exposed in a static air furnace at $982^{\circ} \mathrm{C}$ to $1149^{\circ} \mathrm{C}$ for up to 250 hours. The $\mathrm{NiAl}+\mathrm{Cr}+\mathrm{Zr}$ coatings were selected from processes that produced a composition of about 5at\% chromium, 0.5 at\% zirconium, and an aluminum to nickel ratio of about 1:1. Metallographic evaluations before and after the thermal exposure were used to determine the total coating thickness. The difference in total thickness before and after thermal exposure was a result of inward diffusion of the coating. Thickness changes due to oxidation at the coating surface were assumed to be insignificant. In coated hardware, the change in coating thickness due to diffusion results in the consumption of load bearing cross-section material of thin wall blades and is commonly referred to as wall consumption.

A final set of coating runs were completed to substantiate the performance results observed in laboratory testing. High-pressure turbine blades from a commercial gas turbine engine were manufactured with $\mathrm{NiAl}+\mathrm{Cr}+\mathrm{Zr}$ coatings with a composition of 5.0at\% chromium, $0.3-0.7$ at\% zirconium and an aluminum to nickel ratio of about $1: 1$ by means of the EB-PVD process. The coated blades were included in an endurance test engine and run side by side with platinum aluminide coated hardware. Following engine testing the $\mathrm{NiAl}+\mathrm{Cr}+\mathrm{Zr}$ and platinum aluminide coatings were compared metallographically to determine the relative performance of the $\mathrm{NiAl}+\mathrm{Cr}+\mathrm{Zr}$ overlay coating system in actual engine conditions.

A combination of optical metallography, scanning electron microscopy, and energy dispersive spectroscopy was used to analyze the resultant cross-sections. Coating samples were metallurgically evaluated after coating and after testing by cross sectioning. X-ray fluorescence (XRF) was used to confirm the average composition of the coatings prior to testing. XRF measurements were calibrated by wavelength dispersive spectroscopy measurements made on cross-sections of coatings.

\section{Results}

Both EB-PVD and HVOF processes produced an overlay coating that contained a single phase $\mathrm{NiAl}$ structure ( $\beta$-phase). Figure 2 shows the typical $\mathrm{NiAl}+\mathrm{Cr}+\mathrm{Zr}$ coating microstructure following 
EB-PVD processing. Figure 3 shows the same coating following the vacuum heat treatment at $1093^{\circ} \mathrm{C}$ for 2 hours. A predominantly $\beta$-phase microstructure was retained through the additive region of the coating and an interdiffusion zone (IDZ) was produced with the René N5 substrate. The IDZ was found to contain high refractory phases surrounded by a $\beta$-phase or $\gamma^{\prime}$ phase matrix. Several differences were observed when comparing with a typical $(\mathrm{Ni}, \mathrm{Pt}) \mathrm{Al}$ platinum-modified diffusion aluminide (platinum aluminide), Figure 4 . The ratio of coating additive thickness to the IDZ thickness was found to be about 1:1 for the platinum aluminide but 1:0.2 for the overlay $\mathrm{NiAl}+\mathrm{Cr}+\mathrm{Zr}$ coatings. A majority of the intercolumnar voids seen in the asdeposited state for the $\mathrm{NiAl}+\mathrm{Cr}+\mathrm{Zr}$ EB-PVD coatings were observed to close during subsequent heat treatment. The heat treatment did result in a large coating grain size with localized chemistry differences seen at the grain boundaries.

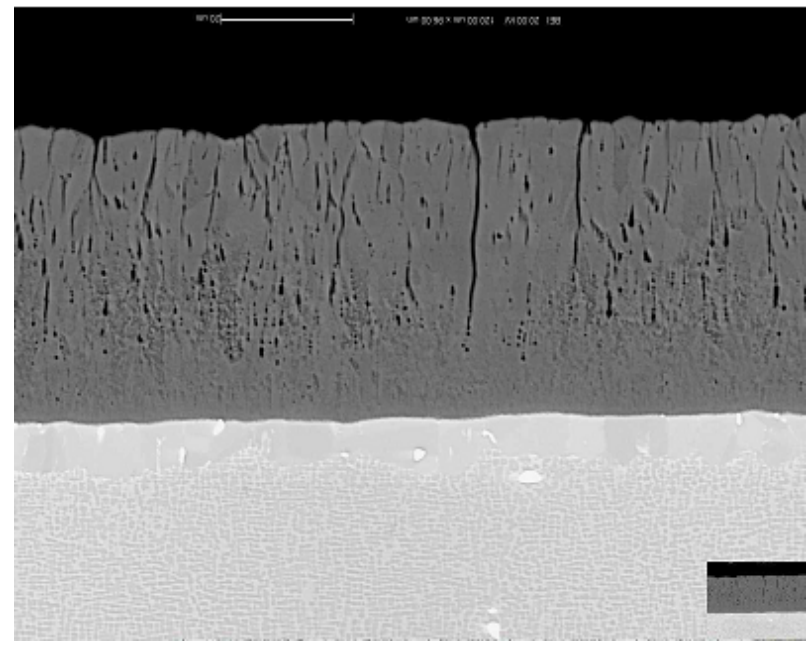

Figure 2. Typical EB-PVD coating microstructure before vacuum diffusion heat treatment (no TBC present)

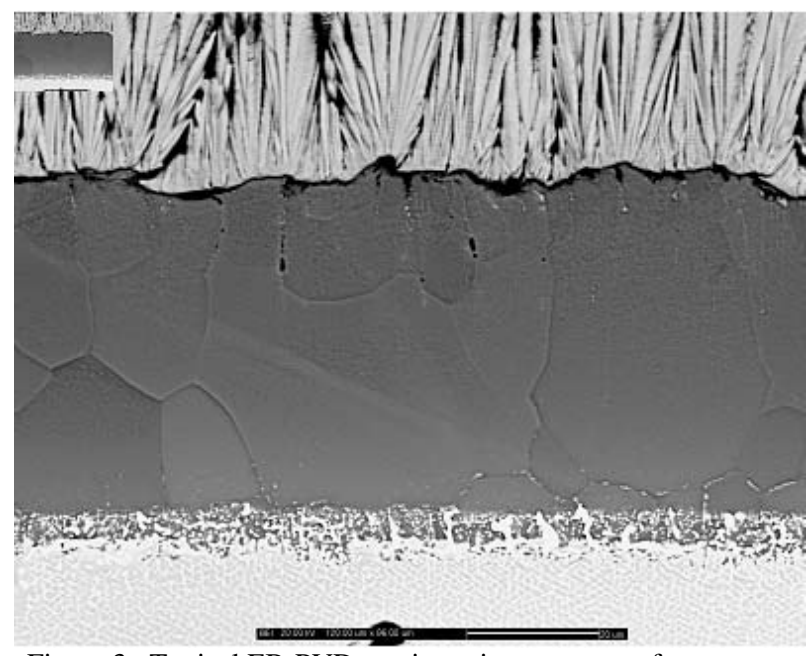

Figure 3. Typical EB-PVD coating microstructure after vacuum diffusion heat treatment $\&$ TBC application

The TBC spallation results from FCT of the EB-PVD processed $\mathrm{NiAl}+\mathrm{Cr}+\mathrm{Zr}$ coatings are plotted in Figure 5. The spallation resistance of the TBC was strongly influenced by the zirconium concentration. A zirconium range from 0.2 to $1.2 \mathrm{at} \%$ exceeded the performance of platinum aluminide baseline (230 cycles average denoted by "baseline") and particularly for levels of 0.3 to $0.7 \mathrm{at} \%$. A local maximum in TBC life was found at $0.5 \mathrm{at} \%$ zirconium [8].

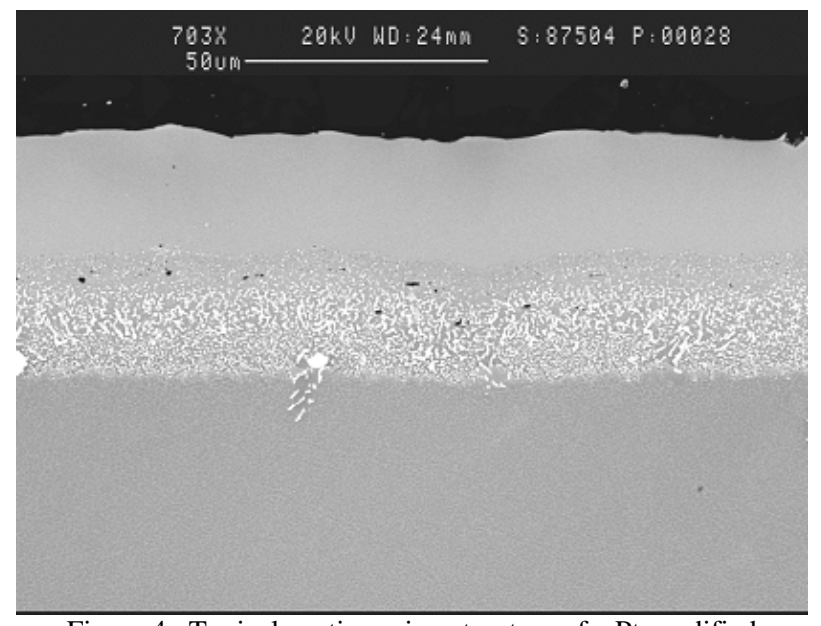

Figure 4. Typical coating microstructure of a Pt-modified diffusion aluminide coating

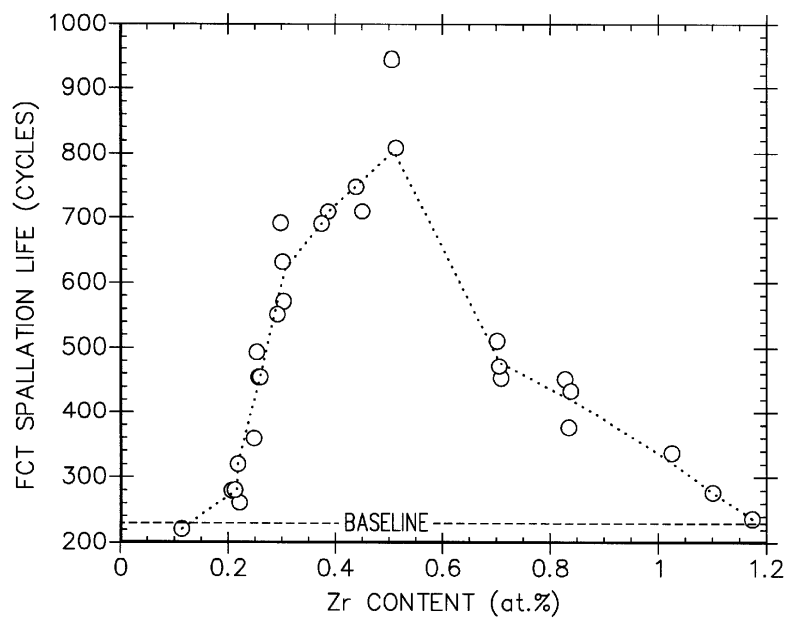

Figure 5. TBC spallation results from $\mathrm{FCT}$ testing of $\mathrm{NiAl}+\mathrm{Cr}+\mathrm{Zr}$ coatings produced by EB-PVD method [8]

TBC spallation lives for the $\mathrm{HVOF}$ processed $\mathrm{NiAl}+\mathrm{Cr}+\mathrm{Zr}$ coatings are plotted in Figure 6. The TBC spallation life was greatest for higher levels of chromium and zirconium. Similar to the EB-PVD processed coatings, a maximum in TBC life was found at 0.5 at $\%$ zirconium with life decreasing at both higher and lower levels. All $\mathrm{NiAl}+\mathrm{Cr}+\mathrm{Zr}$ coatings performed better than the baseline platinum aluminide, which had an average life of 480 cycles in the burner rig cyclic test [8].

CHCO testing lives for $\mathrm{HVOF}$ processed $\mathrm{NiAl}+\mathrm{Cr}+\mathrm{Zr}$ coatings are plotted in Figure 7. All $\mathrm{NiAl}+\mathrm{Cr}+\mathrm{Zr}$ coating chemistries with the exception of the lowest zirconium level, exceeded the performance of the baseline (platinum aluminide baseline had an average performance of 9.4 cycles per micron of coating). As with the TBC spallation lives, higher chromium and zirconium levels were found to be beneficial in the combined oxidation and 
hot corrosion environment. Also similar, a maximum performance was found for the coatings with $0.5 \mathrm{at} \%$ zirconium [8].

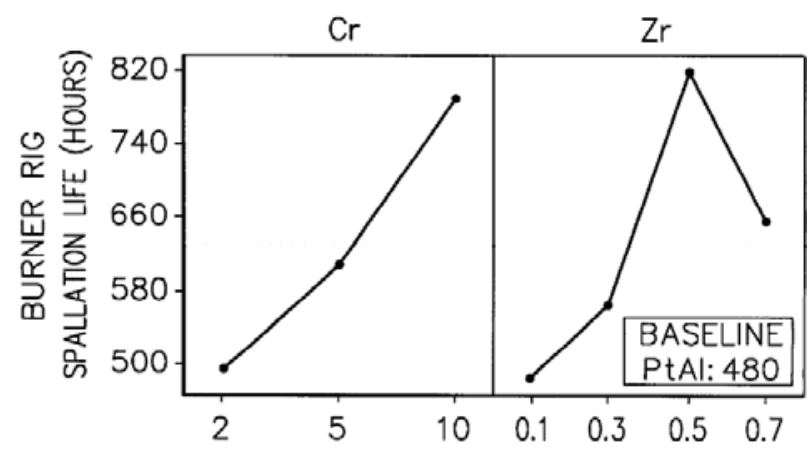

Figure 6. TBC spallation results from cyclic burner testing of $\mathrm{NiAl}+\mathrm{Cr}+\mathrm{Zr}$ coatings produced by HVOF process [8]

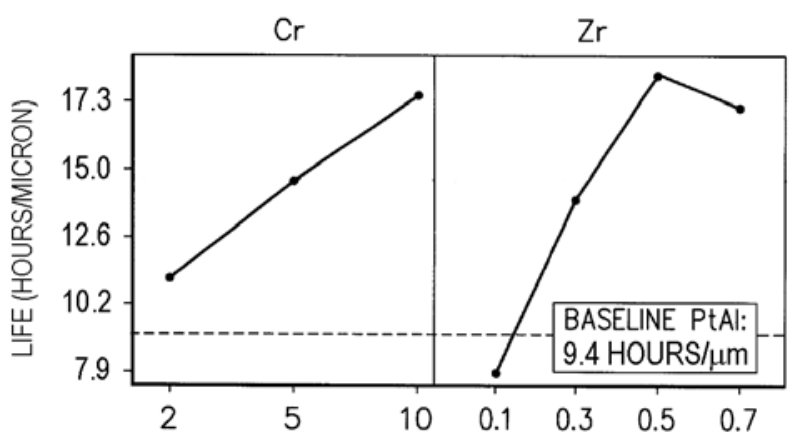

Figure 7. Cyclic hot corrosion and oxidation results of $\mathrm{NiAl}+\mathrm{Cr}+\mathrm{Zr}$ coatings produced by HVOF process [8]

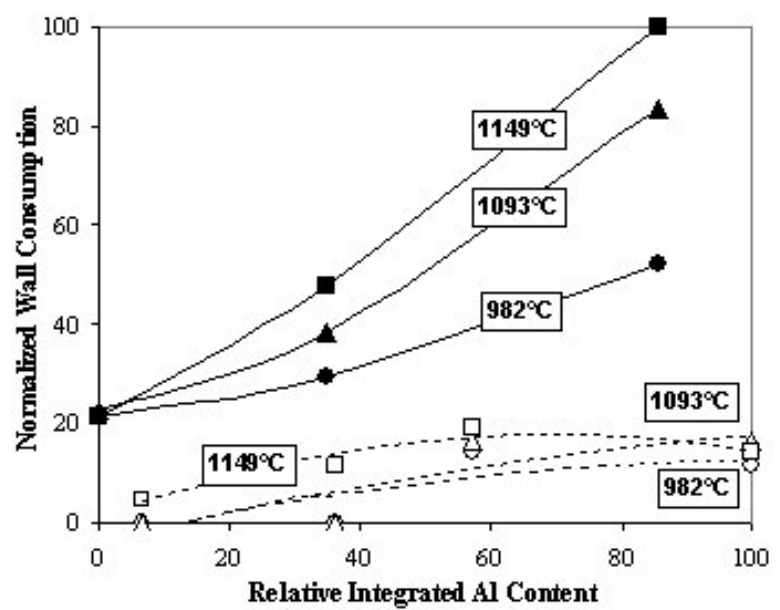

Figure 8. Wall consumption of various coatings after 250 hot hours of exposure: solid symbols = platinum aluminide, open symbols $=\mathrm{NiAl}+\mathrm{Cr}+\mathrm{Zr}$

The results of the elevated temperature exposures of the substrate alloy with $\mathrm{NiAl}+\mathrm{Cr}+\mathrm{Zr}$ and platinum aluminide bond coats are shown in Figure 8. To compare the dissimilar coating types, a relative aluminum content was defined as the product of the average aluminum concentration and the coating thickness. For both coatings, increasing relative aluminum content resulted in greater wall consumption as expected. However, the wall consumption for the $\mathrm{NiAl}+\mathrm{Cr}+\mathrm{Zr}$ coating was about $25 \%$ that of the platinum aluminide. Figure 9 compares a platinum aluminide and $\mathrm{NiAl}+\mathrm{Cr}+\mathrm{Zr}$ coating after thermal exposure before and after a chemical stripping process commonly employed in field service repair. With the $\mathrm{NiAl}+\mathrm{Cr}+\mathrm{Zr}$ coating, the substrate lost about $70 \%$ less thickness when compared with the platinum aluminide.

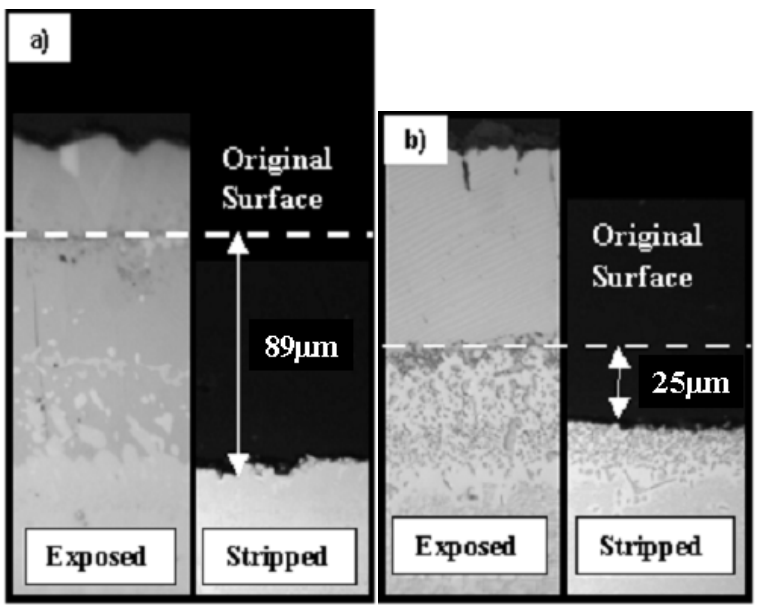

Figure 9. Wall consumption after thermal exposure of (a) platinum aluminide and (b) $\mathrm{NiAl}+\mathrm{Cr}+\mathrm{Zr}$ overlay

Engine tested blades coated with both platinum aluminide and EB-PVD processed $\mathrm{NiAl}+\mathrm{Cr}+\mathrm{Zr}$ coatings were evaluated after endurance engine testing. Figure 10 shows the relative comparison of the coatings at the hot trailing edge location. A blade cross-section for each coating was made at about the trailing edge $50 \%$ span. The platinum aluminide coating suffered extensive rumpling resulting in full TBC spallation while the $\mathrm{NiAl}+\mathrm{Cr}+\mathrm{Zr}$ coating did not rumple and most of the TBC remained intact.

\section{Discussion}

The $\mathrm{NiAl}+\mathrm{Cr}+\mathrm{Zr}$ overlay coatings are a predominantly $\beta$-phase $\mathrm{NiAl}$ coating, as observed in Figures 2 and 3,. Although the density and roughness of the coating was affected by the method of processing, EB-PVD versus HVOF, the coating phase constitution remained consistent. It is believed that the composition of these coatings resulted in the improved durability documented.

Karlsson and Evans predicted that a bond coat with higher yield strength could reduce or prevent the rumpling amplitude change of the bond coat surface from continued thermal cycling [9]. To exploit the benefit of a stronger coating on rumpling resistance, the addition of elements such as zirconium or chromium were found to provide solid solution and/or precipitate strengthening from fine $\alpha$-Cr phases or $\beta$ ' Heusler phases dispersed within the beta phase of the coating $[7,8]$. Figure 11 shows an example of the fine $\alpha$-Cr phases or $\beta$ ' Heusler phases dispersed within the large $\beta$-phase $\mathrm{NiAl}$ grains and additionally a fine $\gamma$ '-phase present at the grain boundaries due to aluminum diffusion into the alloy. Examination of the $\mathrm{NiAl}+\mathrm{Cr}+\mathrm{Zr}$ and platinum aluminide coating surfaces after FCT and burner rig cycling confirmed the reduction 
in surface rumpling and the longer TBC lives. Figure 12 shows the TGO surface after about 100 1-hour FCT cycles. The platinum aluminide displayed extensive rumpling from thermal cycling while the $\mathrm{NiAl}+\mathrm{Cr}+\mathrm{Zr}$ showed minimum surface roughening.

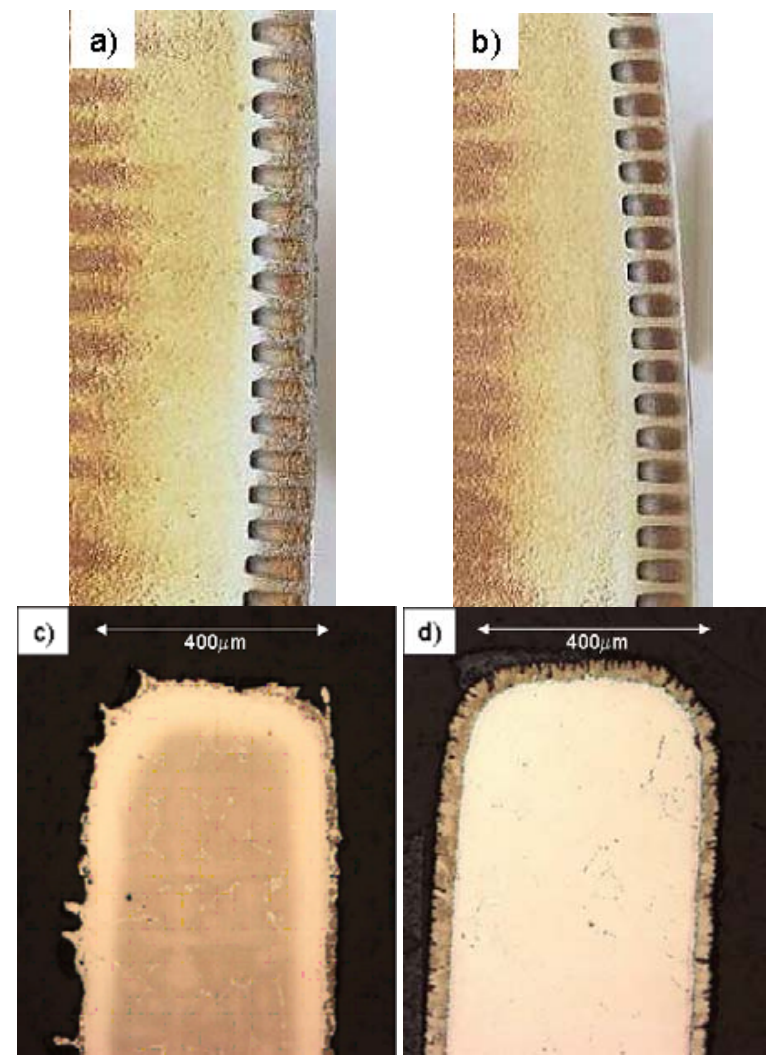

Figure 10. Coating rumpling and TBC damage observed after endurance engine testing of trailing edges of $(\mathrm{a}, \mathrm{c})$ platinum aluminide and (b, d) $\mathrm{NiAl}+\mathrm{Cr}+\mathrm{Zr}$ overlay

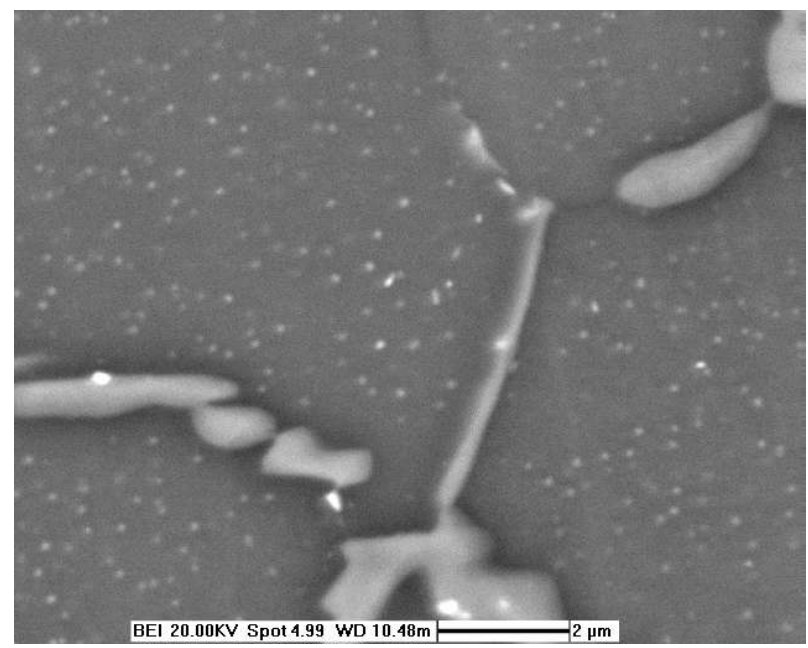

Figure 11. Second phase particulate strengthening of $\beta$-phase $\mathrm{NiAl}+\mathrm{Cr}+\mathrm{Zr}$ overlay coating
A second benefit of the zirconium addition to a $\beta$-phase $\mathrm{NiAl}$ coating composition was to promote the formation of an adherent slow growing $\alpha$-alumina TGO. The effect of reactive elements on environmental coating performance has been discussed for some time. The proposed mechanisms include (1) the formation of oxide pegs which anchor the oxide scale, (2) an increase in the scale plasticity produced by an alteration of the scale structure, (3) an improvement in scale adhesion by elimination of pore formation or vacancy coalescence, (4) a change in the scalegrowth mechanism, and (5) a modification of the scale microstructure [10, 11, 12]. Additionally, prior work has been conducted on bond coatings with zirconium as the reactive element. Schumann et al. and Naveos et al. showed that zirconium segregated to the oxide grain boundaries, possibly resulting in reduced aluminum diffusion into the oxide scale [13, 14].

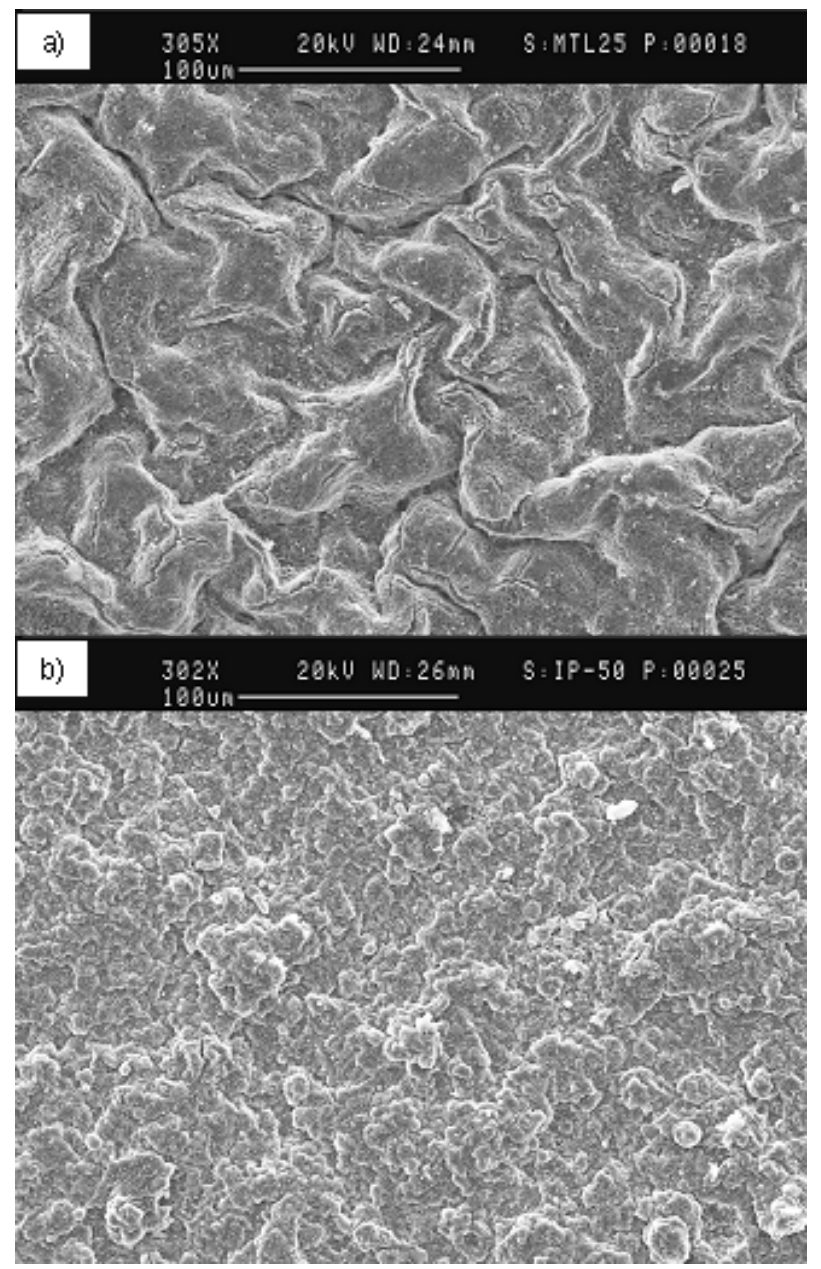

Figure 12. Surface rumpling during cyclic furnace exposure of (a) platinum aluminide and (b) $\mathrm{NiAl}+\mathrm{Cr}+\mathrm{Zr}$ overlay

Another reported benefit is that reactive elements, including zirconium, interact with deleterious tramp elements such as sulfur that contaminate the coating-oxide interface. Smialek showed that the presence of the reactive element in the coating gettered the sulfur and reduced or prevented the preferential segregation to the scale-metal interface [15]. Results from the present work 
further support the effects of zirconium on the oxide scale. Short high temperature thermal exposures on $\mathrm{NiAl}+\mathrm{Cr}+\mathrm{Zr}$ coatings showed that zirconium preferentially concentrates at the coating surface as zirconium oxide during the early stages of oxidation. Figure 13 shows a $\mathrm{NiAl}+\mathrm{Cr}+\mathrm{Zr}$ coating after thermal exposure at $1204^{\circ} \mathrm{C}$ where the bright phase on the surface is zirconium oxide.

In addition to surface segregation, it has been proposed that reactive elements such as yttrium, hafnium and zirconium in a NiAl-based coating composition can lead to preferential oxidation at the coating external surface, forming oxide "pegs" that help improve the mechanical integrity of the alumina scale that forms on the coating $[11,16]$. Figure 14 displays the formation of such pegs in the EB-PVD processed $\mathrm{NiAl}+\mathrm{Cr}+\mathrm{Zr}$ coating. The tortuous path created by "pegging" has been credited with creating an irregular coating-oxide interface that increases the resistance to crack propagation $[11,12,16]$. An optimal amount of reactive element is needed, as too little provides minimal improvement, and too much causes excessive internal oxidation. This work has defined a maximum benefit for TBC spallation and environmental resistance at $0.5 \mathrm{at} \%$ zirconium.

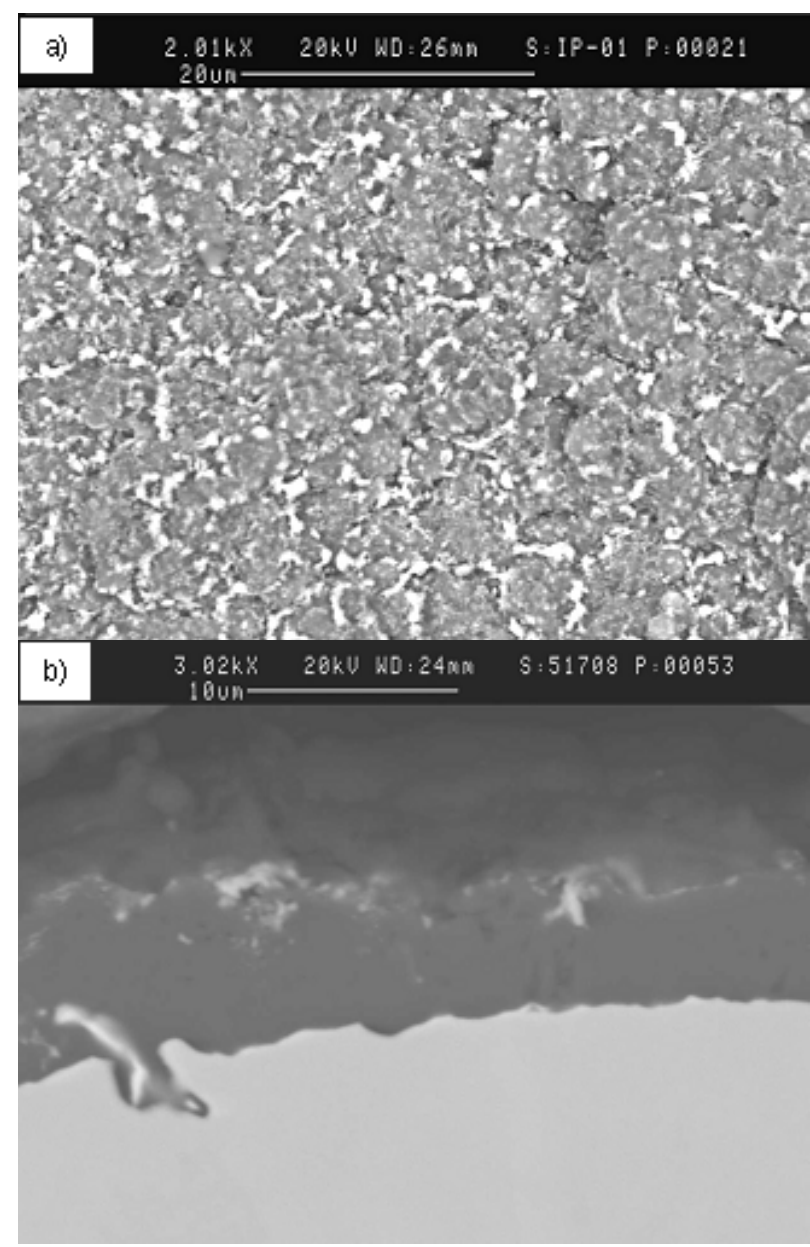

Figure 13. Zirconium (bright phase) segregation to the metaloxide interface after thermal exposure at $1204^{\circ} \mathrm{C}$

Chemical additions other than reactive elements also play important roles in overall coating performance beyond that of
TBC spallation resistance. Chromium is an element commonly found in coatings, for example diffusion aluminides routinely have about $1-2 \mathrm{at} \%$ chromium as a result of diffusion from the substrate. Other coating systems, such as MCrAlY's, specifically contain high levels of approximately 20at\% chromium. The chromium level in the $\mathrm{NiAl}$ system was evaluated in this work to determine an optimum range for durability of the system including TBC adherence, environmental resistance and coatingsubstrate interdiffusion. In addition to the known ability to provide hot corrosion resistance, chromium is believed to enhance the formation of alumina [17]. Similarly, as is illustrated in Figure 6 and 7, increasing chromium content has also been found to be a beneficial element for $\mathrm{NiAl}+\mathrm{Cr}+\mathrm{Zr}$ coating performance.

In addition to the environmental and TBC spallation performance, the $\mathrm{NiAl}+\mathrm{Cr}+\mathrm{Zr}$ coating is believed to provide a benefit over current coating systems by minimizing the interdiffusion between the coating and the substrate. Two potential benefits are anticipated with the $\mathrm{NiAl}+\mathrm{Cr}+\mathrm{Zr}$ overlay system: 1) less interdiffusion could result in less contamination of the thermally grown oxide (TGO) from deleterious substrate elements during the early stages of oxidation and 2) the diffusion zone between the coating and the substrate could be minimized to retain the load bearing cross-section material of thin wall blades.

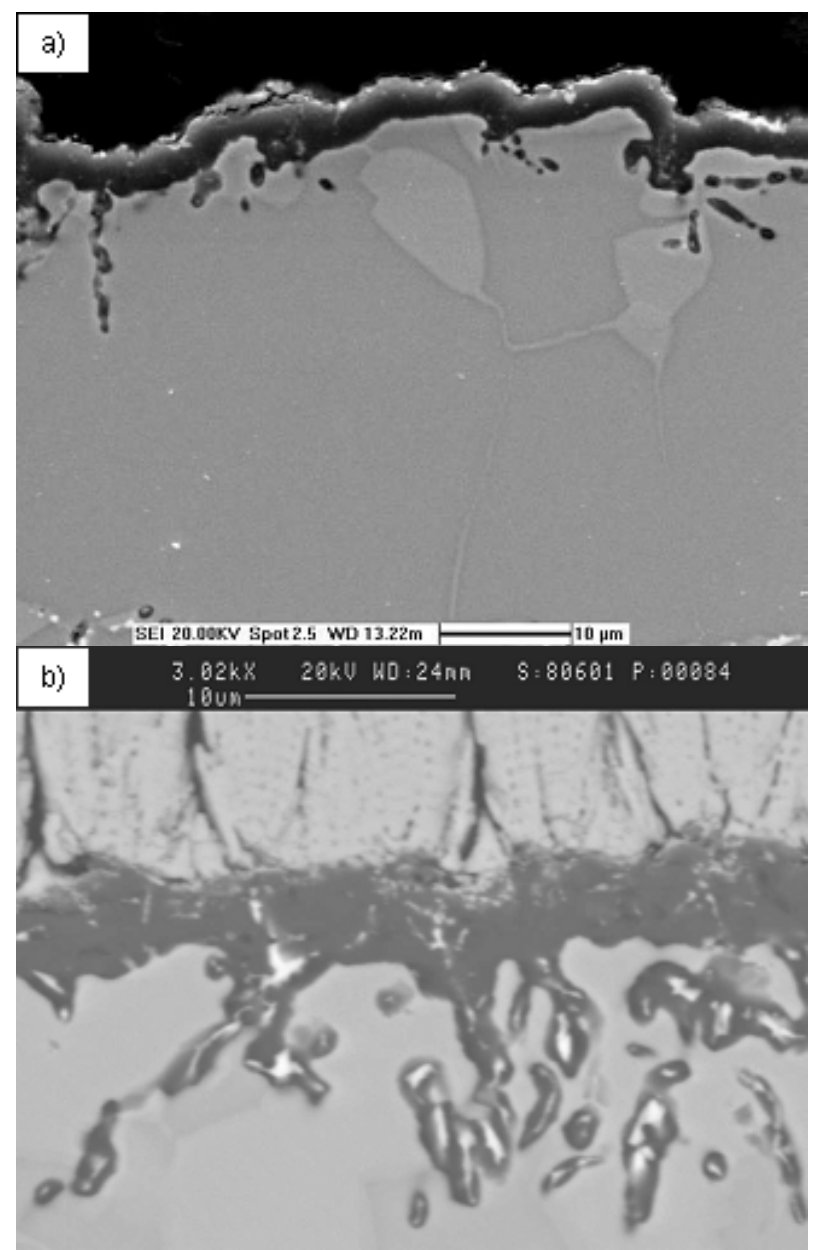

Figure 14. Peg formation during cyclic furnace exposure in $\mathrm{NiAl}+\mathrm{Cr}+\mathrm{Zr}$ overlay coatings: a) $0.2 \mathrm{at} \% \mathrm{Zr}$ and b) $0.8 \mathrm{at} \% \mathrm{Zr}$ 
The $\mathrm{NiAl}+\mathrm{Cr}+\mathrm{Zr}$ coating minimized the interdiffusion (Figure 8) by simultaneously depositing beneficial reactive elements along with the primary coating elements $(\mathrm{Ni}, \mathrm{Cr}$, and $\mathrm{Al})$. This is in contrast with standard diffusion coating processes that relied on nickel outward diffusion and aluminum inward diffusion to form the coating. The differences in elemental activity between the $\mathrm{NiAl}+\mathrm{Cr}+\mathrm{Zr}$ coating and the substrate are reduced by incorporation of $\mathrm{Ni}, \mathrm{Cr}$, and $\mathrm{Al}$ directly into the coating effectively reducing the driving force for diffusion during thermal exposure. Importantly, minimal interdiffusion reduces the transfer of deleterious elements from the substrate into the coating promoting the initial formation and subsequent slow growth of the protective alpha alumina scale. Another positive benefit of the $\mathrm{NiAl}+\mathrm{Cr}+\mathrm{Zr}$ coating is the substantially thinner diffusion layer as compared with traditional diffusion based aluminides. As illustrated in Figure 8 and 9, the $\mathrm{NiAl}+\mathrm{Cr}+\mathrm{Zr}$ coatings showed a benefit over diffusion aluminides for retaining load bearing crosssection during service and increasing the ability to refurbish hardware during engine overhaul for continued use.

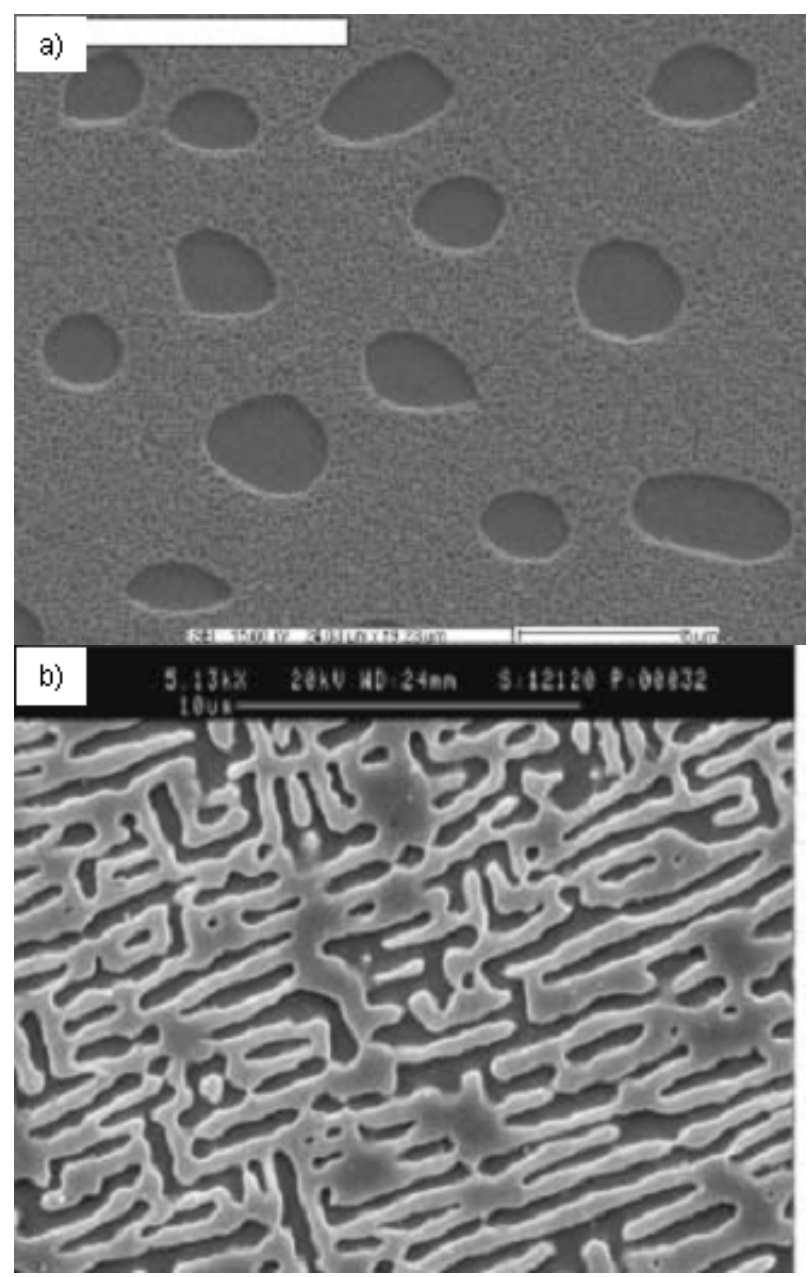

Figure 15. Typical Rene`N5 $\gamma / \gamma^{\prime}$ microstructure observed after endurance engine testing of trailing edges of (a) platinum aluminide and (b) $\mathrm{NiAl}+\mathrm{Cr}+\mathrm{Zr}$ overlay
Endurance engine testing with the EB-PVD processed $\mathrm{NiAl}+\mathrm{Cr}+\mathrm{Zr}$ coatings validated the laboratory results. The $\mathrm{NiAl}+\mathrm{Cr}+\mathrm{Zr}$ coatings rumpled less than platinum aluminide and retained more of the TBC ceramic layer. In regions where TBC had spalled from both coatings, a higher base metal temperature (determined from the $\gamma / \gamma^{\prime}$ microstructure of the substrate alloy) was realized for platinum aluminide coated blades than for $\mathrm{NiAl}+\mathrm{Cr}+\mathrm{Zr}$ (Figure 15). The rumpled platinum aluminide surface debited the heat transfer effectiveness increasing the local temperature. The blades without rumpling had metal temperatures consistent with heat transfer predictions.

\section{Conclusions}

A new GE-Aviation NiAl-based overlay bond coat has been developed to provide durability to thermal barrier coating systems as the need for thermal protection increases. The performance benefit was achieved by engineering the coating composition and deposition processes to reduce coating rumpling during thermal cycling. A major finding has been that the TBC durability was affected by four separate factors.

(i) Zirconium reactive element addition for increasing coating strength and improving scale adherence was critical. Oxide pegging and surface segregation were observed with the addition of zirconium

(ii) Chromium additions along with the zirconium were beneficial. Besides the known corrosion benefit, chromium also improved TBC adherence.

(iii) Overlay processing where $\mathrm{Ni}$ and $\mathrm{Cr}$ were included in the as deposited coating was crucial to reduce interdiffusion. Wall load bearing cross-section will be maintained during extended high temperature operation.

(iv) A reduced tendency for bond coat rumpling resulted in increased TBC adherence and thus lower substrate temperature operation in endurance engine operation.

The coating also satisfies a number of other performance and producibility requirements required for field introduction on turbine airfoils.

\section{Acknowledgements}

EB-PVD processing for this study was done by Reed Corderman and Rit Nardi of GE Global Research and HVOF process by Karl Borneman and Tom Tomlinson of GE Aviation. Metallographic specimen preparation and heat treatment were provided by Don Kirch and Eric Boerger of GE Aviation. Valuable technical consultation was provided by Dave Wortman of GE Aviation and Don Lipkin of GE Global Research.

\section{References}

1. S. Walston, A. Cetel, R. MacKay, K. O’Hara, D. Duhl, and R. Dreshfield, "Joint Development of a Fourth Generation Single Crystal Superalloy”, Superalloys 2004, ed. K.A. Green, T.M. Pollock, H. Harada, T.E. Howson, R.C. Reed, J.J. Schirra, and S. Walston (Warrendale, PA: TMS, 2004), 15-24.

2. W.S. Walston, R.D Field, J.R. Dobbs, D.F. Lahrman and R. Darolia, "Microstructure and High Temperature Strength of NiAl Alloys”, Structural Intermetallics, ed. R. Darolia, J.J 
Lewandowski, C.T. Liu, P.L. Martin, D.B. Miracle and M.V. Nathal (Warrendale, PA: TMS, 1993), 523-532.

3. A. Maricocchi, A. Bartz and D. Wortman, "PVD TBC Experience on GE Aircraft Engines”, Journal of Thermal Spray Technology, 6 (2) (1997) 193-198.

4. V.K. Tolpygo and D.R. Clarke, "Surface Rumpling of a (Ni,Pt)Al Bond Coat Induced by Cyclic Oxidation”, Acta Mater., 48 (2000) 3283-3293.

5. D.R. Mumm, A.G. Evans, and I.T. Spitsberg, "Characterization of a Cyclic Displacement Instability for a Thermally Grown Oxide in a Thermal Barrier System”, Acta Mater., 49 (2001) 2329-2340.

6. I.T. Spitsberg, D.R. Mumm, and A.G. Evans, "On the Failure Mechanisms of Thermal Barrier Coatings with Diffusion Aluminide Bond Coatings”., Mater. Sci, Eng., A415 (2005) 176191.

7. J. Rigney, R. Darolia, W. Walston and R. Corderman., "Nickel aluminide coating and coating systems formed therewith", US Patent 6,153,313.

8. R. Darolia, J. Rigney, and R. Grylls., "Nickel aluminide coating and coating systems formed therewith”, US Patent 6,291,084.

9. A.M. Karlsson and A.G. Evans, "A Numerical Model for the Cyclic Instability of Thermally Grown Oxides in Thermal Barrier Systems”, Acta Mater., 49 (2001) 1793-1804.

10. B.A. Pint, "Experimental Observations in Support of the Dynamic-Segregation Theory to Explain the Reactive-Element Effect”, Oxid Met, 45 (1996) 1-37.

11. J.G. Smeggil, "Some Comments on the Role of Yttrium in Protective Oxide Scale Adherence”, Mater. Sci. Eng., 87 (1987) 261-265.

12. D.P. Whittle and J. Stringer, "Improvements in High Temperature Oxidation Resistance by Additions of Reactive Elements or Oxide Dispersions”, Phil. Trans. R. Soc. Lond. A, 295 (1980) 309-329.

13. E. Schumann, J.C. Yang, M. Ruhle, and M.J. Graham, "HighResolution SIMS and Analytical TEM Evaluation of Alumina Scales on B-NiAl Containing Zr or Y”, Oxid. Met., 46 (1996) 3749.

14. S. Naveos, G. Oberlaender, Y. Cadoret, P. Josso, and M.P. Bacos, "Zirconium Modified Aluminide by a Vapor Pack Cementation Process for Thermal Barrier Applications: Formation Mechanisms and Properties”, Mat. Sci. Forum, 461-464 (2004) 375-382.

15. J. L. Smialek, "The effect of sulfur and zirconium co-doping on the oxidation of NiCrAl", High Temp Mat Chem IV, 88-5 (1987) 75-81.

16. I.M. Allam, D.P. Whittle, and J. Stringer, "Improvements in Oxidation Resistance by Dispersed Oxide Additions: $\mathrm{Al}_{2} \mathrm{O}_{3}$ Forming Alloys”, Oxid Met, 13 (1979) 381-401.
17. J.H Wood and E.H. Goldman, "Protective Coatings", Superalloys II, ed. C.T. Sims, N.S. Stoloff, and W.C. Hagel (New York, NY: John Wiley \& Sons, 1987), 359-384. 